\title{
Non-Inverting Cascaded Bidirectional Buck-Boost DC-DC Converter with Average Current Mode Control for Lithium-Ion Battery Charger
}

\author{
Heri Suryoatmojo \\ Department of Electrical Engineering \\ Institut Teknologi Sepuluh Nopember \\ Surabaya, Indonesia \\ *suryomgt@gmail.com
}

\author{
Indra Anugrah Pratama \\ Department of Electrical Engineering \\ Institut Teknologi Sepuluh Nopember \\ Surabaya, Indonesia \\ indra.pratama3224@gmail.com
}

\author{
Soedibyo \\ Department of Electrical Engineering \\ Institut Teknologi Sepuluh Nopember \\ Surabaya, Indonesia \\ soedib@ee.its.ac.id
}

\begin{abstract}
In order to develop renewable energy, it also needs to enhance the developing of supporting elements. For example, lithium-ion batteries as a component of energy storage. Lithium-ion batteries ( $\mathrm{Li}$-ion) have been chosen as energy storage devices for portable equipment, unmanned Aerial Vehicle (UAV) and grid storage systems. But there is a problem such as the process of charging the battery for UAV. Conventional converters used in those chargers have disadvantages such as limited power, lower voltage gain and also high current stress. Therefore, such converters are not efficient to be used for charging the battery. This paper proposes a cascaded bidirectional buck-boost converter for charging the battery. This converter can be operated bidirectional and have better rated power and higher voltage gain. Also, this topology has the same polarity with the input. From the test results, the converter can work in either forward or backward power flow. This converter is working in both buck or boost mode and has an efficiency of $83 \%$ in buck mode and $81 \%$ for boost mode. The charging process is about 83 minutes until SOC approximately $90-95$.
\end{abstract}

Keywords - battery charger, cascaded bidirectional buck boost converter, constant current, li-ion introduction.

\section{INTRODUCTION}

In the past few years, efforts to reduce the effects of climate change, reduce air pollution generated by energy, coupled with the threat of depletion of existing fossil energy, have encouraged research and development on renewable energy. The development of renewable energy technology encourages other technology developments such as lithiumion batteries as a component of energy storage. Lithium-ion (Li-ion) batteries are widely used because of their good performance. Such as having high specific energy, high energy density, high efficiency and long-life span. Especially its use in aircraft applications such as Unmanned Aerial Vehicle (UAV). The next thing that becomes a problem is when it is applied to UAV.

Due to the long charging time compared to UAVs that use gasoline as fuel, this also happens to other portable equipment. So that the capability to charge the battery quickly is the main feature that an industry must achieve. Therefore, a converter topology that can work in both forward and reverse directions with better efficiency are required.

This research proposes a topology that can work in both directions and has a better capacity and a better voltage gain. The proposed converter has an advantage that the current stress and losses in the switching are smaller than the general converter. In this study, the converter will be tested on Li-ion batteries. Li-ion batteries were chosen because of its good performance and usually the type of battery that is widely used in UAVs. The bidirectional mode is also necessary for the UAV itself, thereby the test will be done when charging and discharge, along with their typical application. Therefore, a cascaded bidirectional buck-boost converter has been proposed to gain more flexibility and lower current stress in order to improve overall efficiency.

\section{METHODS}

\section{A. Converter Technology \\ 1) Lithium-ion Battery}

The production of lithium-ion batteries has increased significantly since the first introduction on the market in 1991 due to its good performance, which is associated with high specific energy, energy density, specific power, efficiency and relatively long life for lithium-ion batteries. Lithium-ion batteries were originally used for electronic equipment such as mobile phones, cameras, laptops, followed by a larger scale use in automotive and finally in industrial technology as an energy storage device [1]. But the Li-Ion battery also has some disadvantages. Which is more vulnerable than other batteries, reduced capacity as the time of use, expensive manufacturing costs and relatively new technology. Thus, it still needs further development to reach the maximum potential of the Li-Ion battery [2].



Fig. 1. Bidirectional buck-boost DC-DC circuit

Fig. 1 shows a bidirectional converter used in the model. In this discussion we will conduct an overall analysis on how the converter works in continuous current mode or CCM. Because 
the design we choose has a lower input voltage than the output voltage value, this converter will work in boost mode, where the S1 switch will always ON and S2 always OFF, and the S4 will operate to adjust the output voltage of the converter [4].

\section{a) Analysis of boost mode closed switches condition}

As the $\mathrm{S} 1$ switch is continuously on, this converter works in boost mode and we will focus on the S4 switch where the task is to control the value of the output voltage [5]. When the S4 switch is on, the S3 switch would isolate the output of the converter and input voltage would supply the inductor with energy. Fig 2. Shows converter in boost mode.

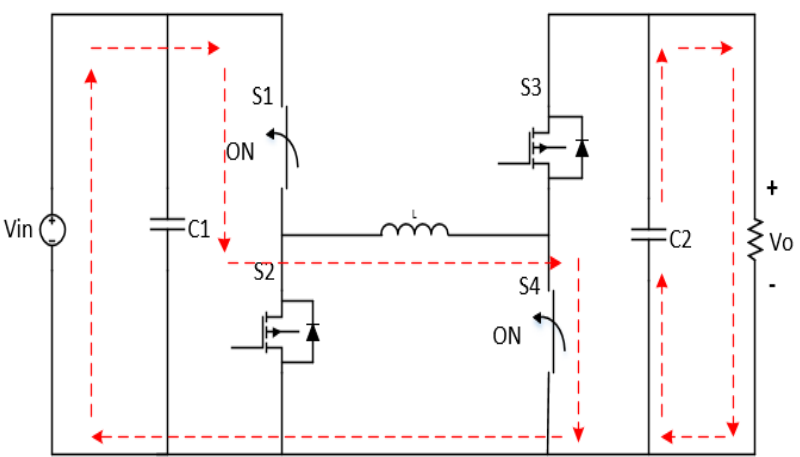

Fig. 2. Converter circuit with switches S1 and S4 closed in boost mode

When the S4 switch is closed. The equations that can be derived are as follows:

$$
\begin{aligned}
& V_{\text {in }}=V_{L}=L \frac{d l}{d t} \\
& \frac{d i_{L}}{d t}=\frac{\Delta i_{L}}{t_{\text {on }}}=\frac{\Delta i_{L}}{D T}=\frac{V_{\text {in }}}{L} \\
& \Delta i_{L_{\text {on }}}=\frac{\left(V_{\text {in }}\right) D T}{L}
\end{aligned}
$$

b) Analysis of boost mode open switches condition

When the S4 is open, the output side will receive energy from the supply and also from the inductor so it can generate output voltage value greater than the input. Figure 2.3. Below is the equivalent set of converters when the $\mathrm{Q}$ switch is open. The equations that can be derived from the circuit are:

$$
\begin{aligned}
& V_{\text {in }}-V_{o}=V_{L}=L \frac{d I}{d t} \\
& \frac{d i_{L}}{d t_{\text {off }}}=\frac{\Delta i_{L}}{(1-D) T}=\frac{V_{\text {in }}-V_{o}}{L} \\
& \Delta i_{L_{\text {off }}}=\frac{\left(V_{\text {in }}-V_{o}\right)(1-D) T}{L}
\end{aligned}
$$

Equations 2.3 and 2.6 can be substituted to find the equation for the voltage output in boost mode:

$$
\begin{aligned}
& \Delta i_{L_{o n}}+\Delta i_{L_{o f f}}=0 \\
& \frac{\left(V_{i n}\right) D T}{L}+\frac{\left(V_{i n}-V_{o}\right)(1-D) T}{L}=0 \\
& V_{S}(D+1-D)-V_{o}(1-D)=0 \\
& V_{o}=\frac{V_{i n}}{1-D}
\end{aligned}
$$

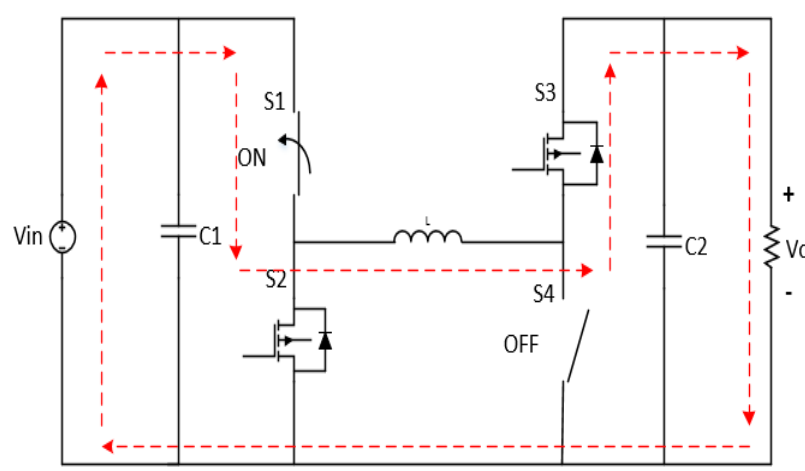

Fig. 3. Converter circuit with switches S4 open in buck mode

From the equation we can calculate that the output voltage is inversely proportional to the duty cycle. We can conclude that the greater the duty cycle, the higher the output voltage will be produced. Fig 3. Shows converter in buck mode.

\section{c) Analysis of buck mode close switches condition}

Since this converter is two converters arranged in Cascade, where the buck converter is followed by a boost converter. This converter can act as a boost, when the voltage input is smaller than its voltage output. Buck-boost when input and output have the same voltage. And the buck mode when the voltage input value is greater than the output voltage. When the converter works as a buck, S1 will work as a switch and the S4 will always be off, so we can get the equivalence of buck converters. At S1 conduction then S2 will work as a diode and isolate the inputs [5]. Figure 4 is the equivalent circuit of the converter where when $\mathrm{S} 1$ is in the conduction stage, the following equation is obtained.

$$
\begin{aligned}
& V_{\text {in }}=V_{L}+V_{o} \text { and } V_{L}=L \frac{d I}{d t} \\
& V_{\text {in }}=L \frac{d I}{d t}+V_{o} \\
& V_{\text {in }}=L \frac{\Delta I}{t_{\text {on }}}+V_{o}
\end{aligned}
$$

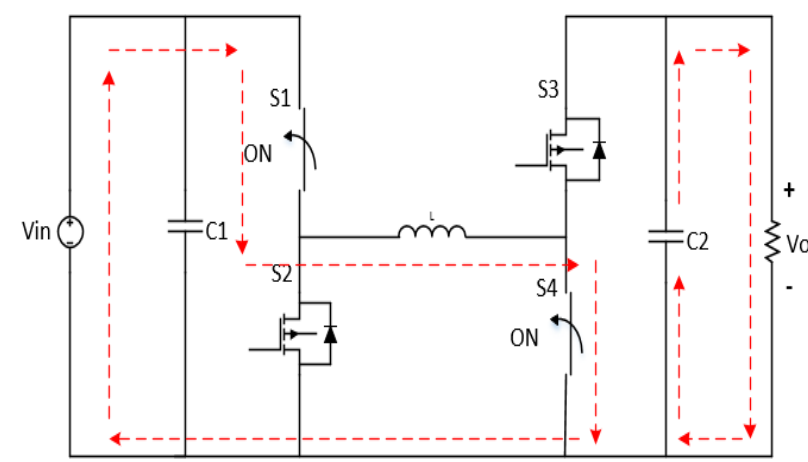

Fig. 4. Converter circuit with switches S1 closed in buck mode

\section{d) Analysis of buck mode open switches condition}

Fig 5. Shows Converter circuit with switches S1 open in buck mode. When S1 is open, then S2 which works as a diode will be in forward biased condition so that the inductor $\mathrm{L}$ will release the stored energy to the load. The equations that can be derived in this mode are:

$$
\begin{aligned}
& V_{o}=V_{L} \text { and } V_{L}=L \frac{d I}{d t} \\
& V_{o}=L \frac{d I}{d t}
\end{aligned}
$$




$$
\begin{aligned}
& V_{o}=L \frac{\Delta I}{t_{o f f}} \\
& L \Delta I=\left(V_{o}\right) t_{o f f}
\end{aligned}
$$

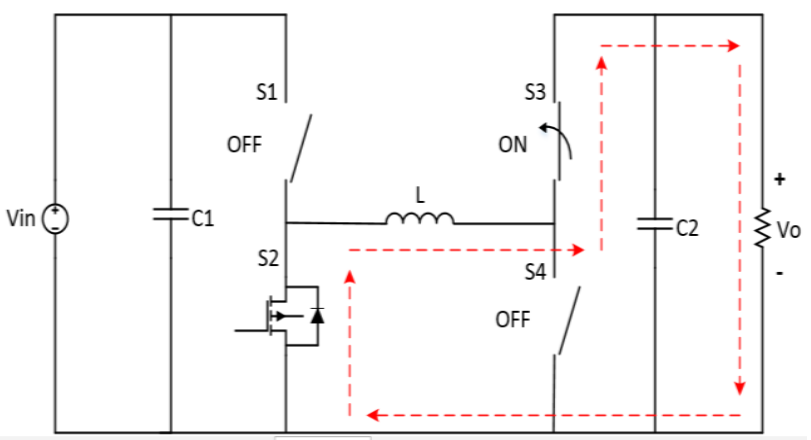

Fig. 5. Converter circuit with switches S1 open in buck mode

The results in equations 13 and 17 can be substituted into the following equation:

$$
\begin{aligned}
& V_{\text {in }}=V_{o} \frac{t_{\text {off }}}{t_{\text {on }}}+V_{o} \\
& V_{\text {in }}=V_{o}\left(1+\frac{t_{\text {off }}}{t_{\text {on }}}\right) \\
& V_{\text {in }}=V_{o}\left(1+\frac{(1-D)}{D}\right) \\
& V_{o}=V_{\text {in }} \mathrm{D}
\end{aligned}
$$

The output voltage of the converter is directly proportional to the duty cycle value. The higher the duty cycle value will result in the higher output voltage. The converter in Buck mode has an output voltage value equal to or less than the input voltage.

3)

\section{Battery Charging Method}

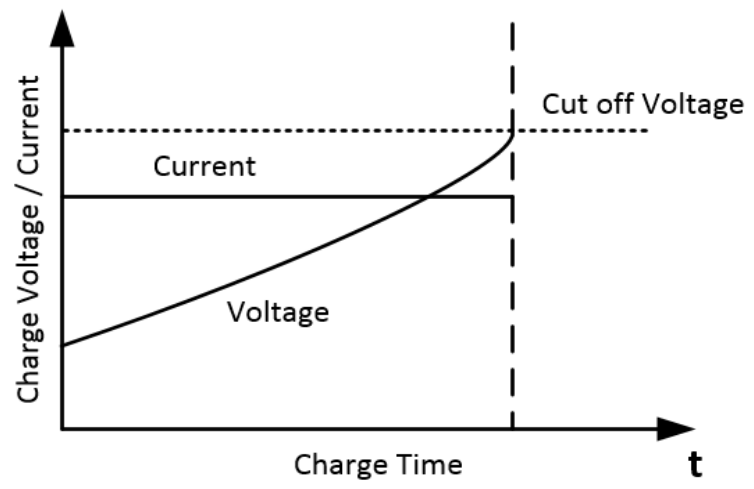

Fig. 6. Battery charging process using constant current method

Battery consists of one or more electrochemical cells with external connections that provide power to the electronic equipment. In the battery there is an electrochemical process that can convert the chemical energy into electrical energy [7]. In the Li-Ion batteries, chemical energy can turn into electrical energy and vice versa. These two processes are called the charge and the discharge process.

The charging process occurs by regenerating the electrode and the solution in the battery by flowing the current into the battery. Battery with a reversible reaction is a secondary battery. While the battery that has a reaction that cannot be reversed is the primary battery. The battery that we use is a Lithium-Ion battery. This battery is a secondary battery because it can be reused or the reactions that occur can be reversed. There are several methods to adjust the output power of the converter based on voltage and current. This method is called Constant Current (CC) and Constant Voltage (CV). Constant current is a method for charging a battery by limiting the current that flows to the battery, thereby minimizing the potential damage that can be done to the battery. But the drawback of the constant current method is that the battery cannot reach $100 \%$ SOC [8], although the voltage has reached a rating that corresponds to the maximum voltage or voltage cut off. The battery is not in the maximum SOC due to an over potential that occurs due to the interaction of battery internal resistance with flowing currents. Fig. 6 above shows the process of charging the battery with a constant current method.

\section{4) Current Control Methods}

To generate a constant current on the converter output we need a method or way to regulate the performance of the semiconductor. In this section it will be discussed about what control methods are used to generate constant current values on the converter output.

\section{a) PID Controller}

Basically, this PID controller sets the output value of the converter flow by changing the duty cycle so that the existing current value will match the setpoint value set.

TABLE I. CHARACTERISTIC OF P, PI, AND PID CONTROLLER

\begin{tabular}{|l|l|l|l|l|}
\hline Function & Rise Time & \multicolumn{1}{|c|}{$\begin{array}{c}\text { Settling } \\
\text { Time }\end{array}$} & $\begin{array}{c}\text { Error } \\
\text { Steady } \\
\text { State }\end{array}$ & Overshoot \\
\hline $\mathrm{Kp}$ & Decrease & Decrease & Decrease & Increase \\
\hline $\mathrm{Ki}$ & Decrease & Decrease & Eliminate & Increase \\
\hline $\mathrm{Kd}$ & $\begin{array}{l}\text { Tiny } \\
\text { Change }\end{array}$ & $\begin{array}{l}\text { Tiny } \\
\text { Change }\end{array}$ & $\begin{array}{l}\text { Tiny } \\
\text { Change }\end{array}$ & Decrease \\
\hline
\end{tabular}

Controller $\mathrm{P}$ is used to reduce steady state errors and reduce rise time. However, a $\mathrm{Kp}$ value that is set too large will result in an overshoot that can make the output value oscillate.

But controller $\mathrm{P}$ cannot generate output values that match the specified setpoint, because controller $\mathrm{P}$ cannot eliminate the error value at the time of steady state. Therefore, an PI controller is required that can eliminate steady state errors.

This PI controller is considered to reduce rise time and settling time, but in this control, it has a high overshoot value so that the output value can oscillate.

To get a good output, the PID controller is used. In addition to being able to reduce overshoot, this controller can reduce rise time and settling time and also has a constant output value.

\section{b) Iteration and branching functions}

Basically, iteration is a repetitive execution of a command as long as the conditions are fulfilled. A program that has the main structure of an iteration function is a loop. The function that is used is called the while function. Branch function is a function that can create another command according to the corresponding condition.

While function in a program is used to execute a command in a program while considering whether the conditions are fulfilled or not. If the conditions are fulfilled, then it will keep 
executing until the conditions are not fulfilled then the program ends. If is a branch function that is used to check the condition of a statement and also execute the command based on the condition stated beforehand. Therefore, several desired commands can be chosen based on the given results.

\section{B. Design, simulation, and implementation}

\section{1) System Block Diagram}

To be able to implement a converter that can work as a buck or boost, work in two directions, and can be used for battery charging. We designed a battery charger using the cascaded bidirectional buck-boost DC-DC converter. Equipment schemes can be seen below:

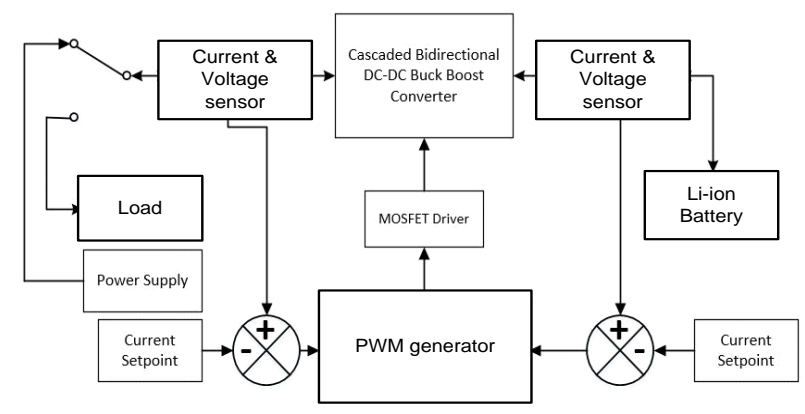

Fig. 7. System block diagram

In addition to the main converter, there is also a series of MOSFET drivers, for switching, current and voltage sensors and microcontrollers as a tool that control the work of each equipment and also as a module to retrieve data from existing equipment.

\section{2) Battery Charging Algorithms}

Figure 8. is a flowchart for battery charging. Supply DC is used as a source of voltage and has been adjusted to have less than the voltage cut-off battery, so the converter will work in boost mode. if the supply-side voltage decreases then the sensor will work and adjust the driver to allow the converter to work as a buck. The charging process uses the CC method and then the data is taken such as voltage and current. The data will be plotted so we can get the battery charging curve.



Fig. 8. Flowchart of battery charging

\section{3) Lithium-ion Battery Charger Design}

We use a three-cell lithium-ion battery that is assembled in a series so that the voltage Reaches $12.6 \mathrm{~V}$. The battery voltage at the initial condition corresponds to the datasheet of $3.7 \mathrm{~V}$ with the capacity of $2600 \mathrm{mAh}$ each cell. Maximum discharge current up to $3 \mathrm{C}$ or $7.8 \mathrm{~A}$ and discharge cut-off voltage is 2.75 standard current and voltage at the time of charging is 1.3 Ampere and 4.2 Volt. By arranging the batteries in the series, we will get $12.6 \mathrm{~V}$ voltage and 2600 $\mathrm{mAh}$ battery capacity in full condition or SOC $100 \%$.

\section{TABLE II. LITHIUM-ION BATTERY CHARGER DESIGN}

\begin{tabular}{|l|l|}
\hline \multicolumn{1}{|c|}{ Parameter } & \multicolumn{1}{c|}{ Value } \\
\hline Constant Current & $1,1 \mathrm{~A}$ \\
\hline Total Cell & 3 \\
\hline Voltage cut-off & $12.6 \mathrm{~V}$ \\
\hline
\end{tabular}

As for the design of Li-ion battery charger can be seen in table 2. It can be seen on the datasheet that the charging nominal for the Li-ion battery is $0.5 \mathrm{C}$ or $1.3 \mathrm{Amps}$, but for reliability purposes, the selected current is lowered to 1.1 Amps. So if an error occurs, the error does not cause significant damage to the battery or the other components.

\section{4) Bidirectional DC-DC Converter}

We will specify the value of the parameters of the converter that we will implement i.e. input voltage (Vin), Output voltage (Vo), frequency switching (FS), Power (P), ripple inductor flow, ripple voltage capacitor. Determining the parameters should also consider the availability of components on the market and the availability of equipment in the laboratory. The purpose of determining components of the converter is to ensure that the converter can meet our expected results and make the results closest to our calculation according to the analysis we provide in the beginning of the literature survey which is in CCM condition. Since the converter has a smaller input voltage than the output voltage, then this converter works in boost mode. These parameters can be seen in Table 3 .

TABLE III. TABLE.3 CONVERTER PARAMETER

\begin{tabular}{|l|l|}
\hline \multicolumn{1}{|c|}{ Voltage Input $\left(\mathrm{V}_{\text {in }}\right)$} & \multicolumn{1}{c|}{$\mathbf{1 0 . 8 ~ V}$} \\
\hline Voltage Output $\left(\mathrm{V}_{\mathrm{o}}\right)$ & $12.6 \mathrm{~V}$ \\
\hline Power Output $\left(\mathrm{P}_{\mathrm{o}}\right)$ & $25.2 \mathrm{Watt}$ \\
\hline Switching Frequency $\left(\mathrm{f}_{\mathrm{s}}\right)$ & $20 \mathrm{kHz}$ \\
\hline Inductor Ripple Current & $8 \%$ \\
\hline Capacitor Ripple Voltage & $1 \%$ \\
\hline Voltage Input $\left(\mathrm{V}_{\mathrm{in}}\right)$ & $10.8 \mathrm{~V}$ \\
\hline
\end{tabular}

5) Converter simulation for battery charging

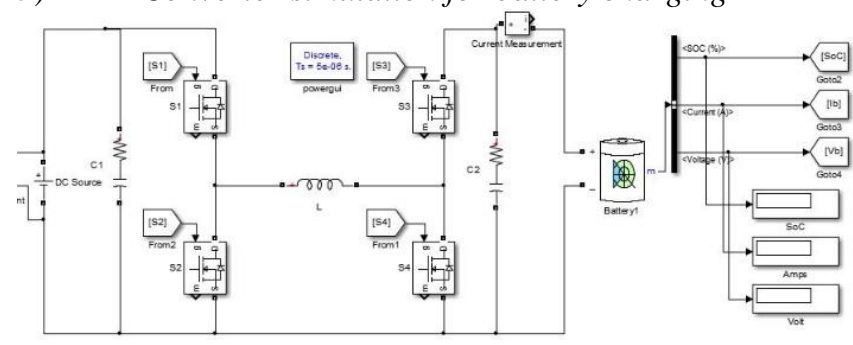

(a) 


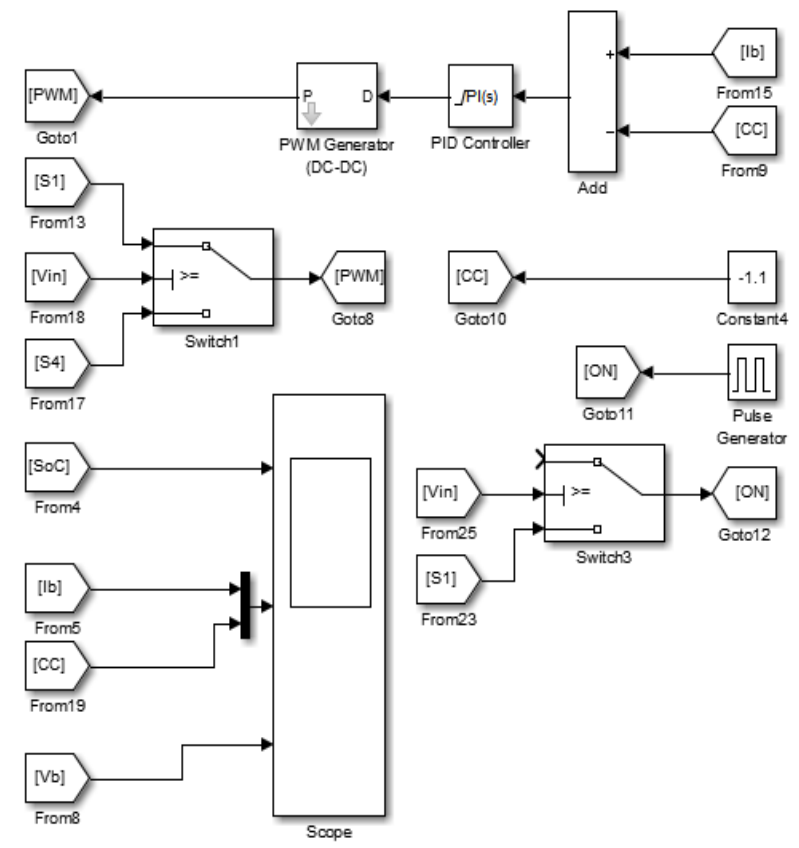

(b)

Fig. 9. Simulation of (a) a cascaded bidirectional buck-boost dc-dc converter (b) a constant current controller

Battery charging simulation is done using a constant current method. Constant current Mode is the charging method by regulating how the current is constantly charged so as not to cause overheating during battery charging. Figure 9 is the result of the simulation of charging lithium-ion batteries using MATLAB software. The constant current Setpoint method is set at 1.1 A according to the design and values of $\mathrm{Kp} 10$ and $\mathrm{Ki} 0.05$.

The switches in the simulation are used to detect when the input voltage value operates as a buck or boost, when the input voltage value is below the output voltage value then the converter works as a boost and when the voltage value is above the output voltage value then the converter works as a buck. The next of Fig. 10 was obtained results from battery charging simulation using a constant current method.

In the picture (a) there is a current approaching the average value of 1.1 Amps but because of the PI controller's value the obtained results are quite close to but there are still some ripple in the end.

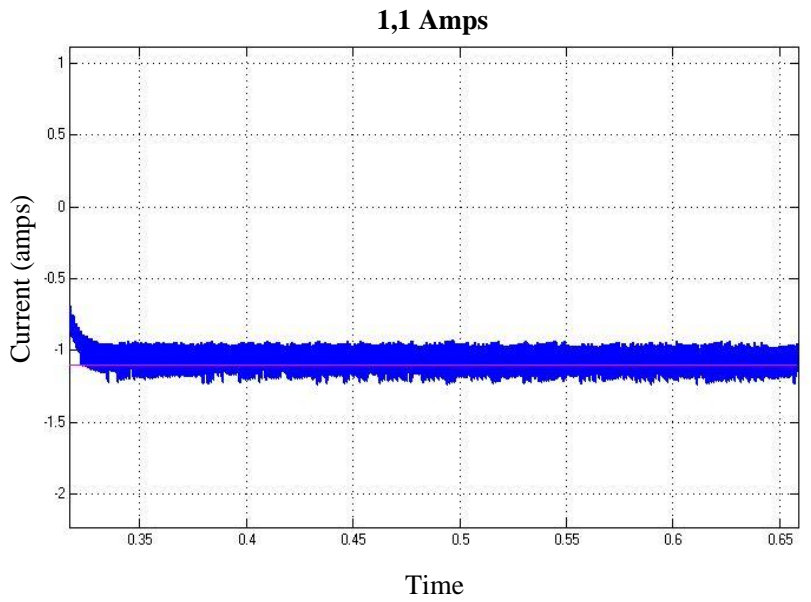

(a)

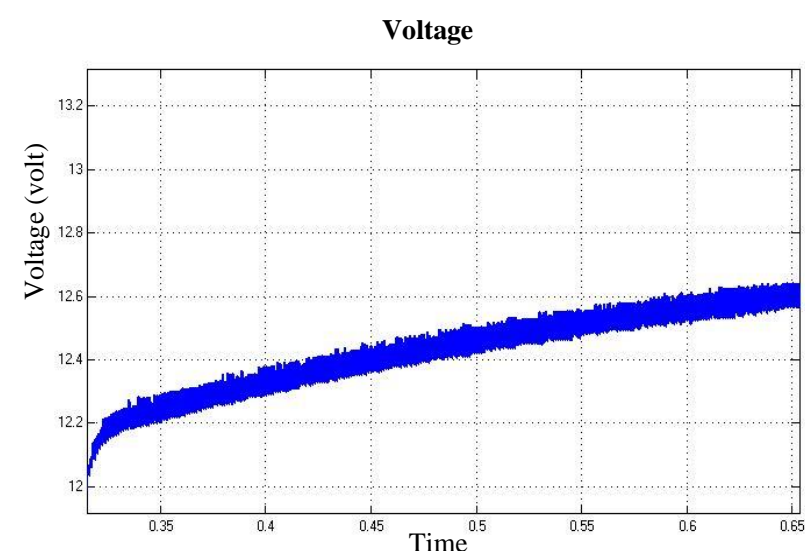

(b)



(c)

Fig. 10. Charging battery simulation results (a) current (b) voltage and (c) SOC

But because the value is approaching the set points, it can be said the converter can work according to the design. So, it already meets the expectation. Then, in the picture (b) we get the value of voltage that continuously rises as the time passes.

This indicates that the value of the SOC present on the battery increases, because when it is viewed from the battery OCV curve then the SOC value of the battery increases as the battery voltage level increases. It can be proved also in the next simulation that the condition seen on the battery where there is an increase in SOC indicates that the battery is being charged. Next, how to read the flowchart of the charger we have designed. The process starts from reading the battery voltage, if the battery voltage is less than $12.6 \mathrm{~V}$ then it is assumed that the battery is not in full condition. Therefore the battery charging process will begin. 


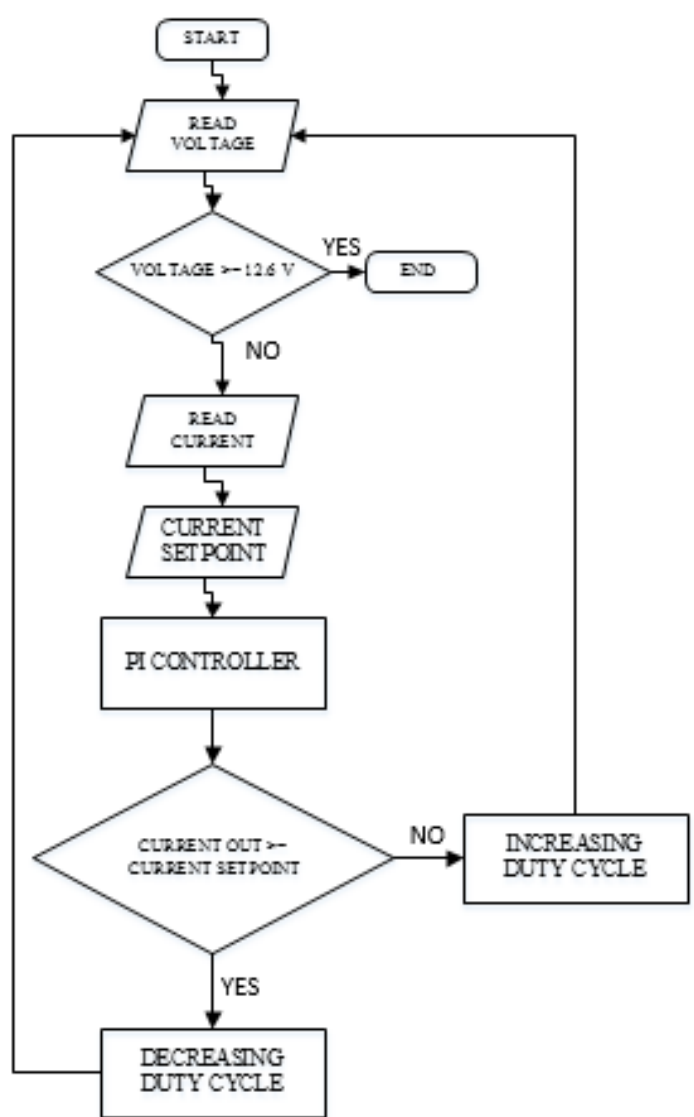

Fig. 11. Flowchart of constant current simulation

This constant current is obtained by changing the duty cycle value in S4 while S1 is always on. After that the value that is owned as output will be used as feedback for the next compared to the setpoint value. As long as the setpoint value has not reached zero, the duty cycle will continue to change until it reaches zero.

Then the constant current battery charging process is obtained. Next is to re-detect the battery voltage, when it reaches 12.6 volts then it is said that the battery is already in maximum charging condition using the constant current method.

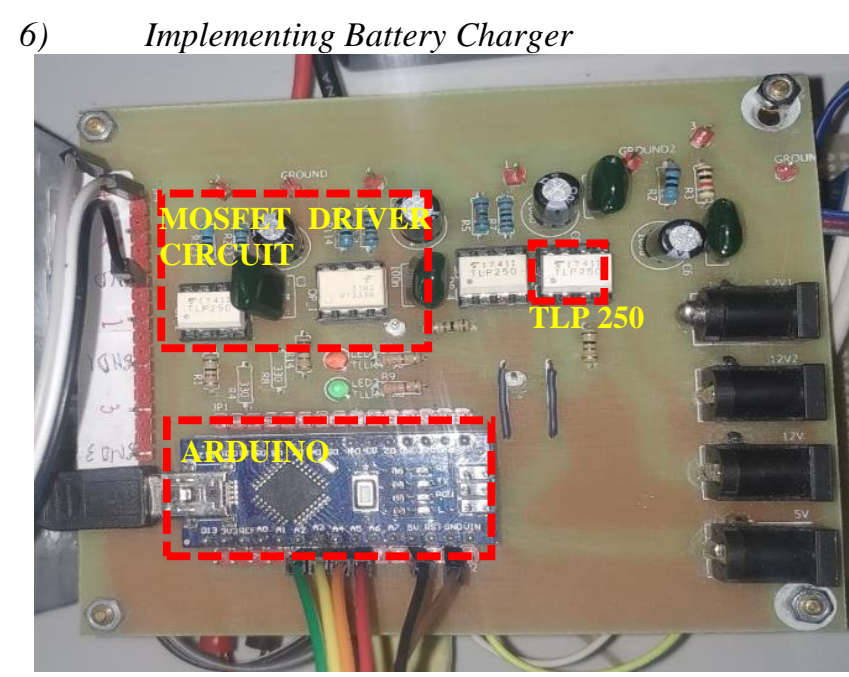

(a)

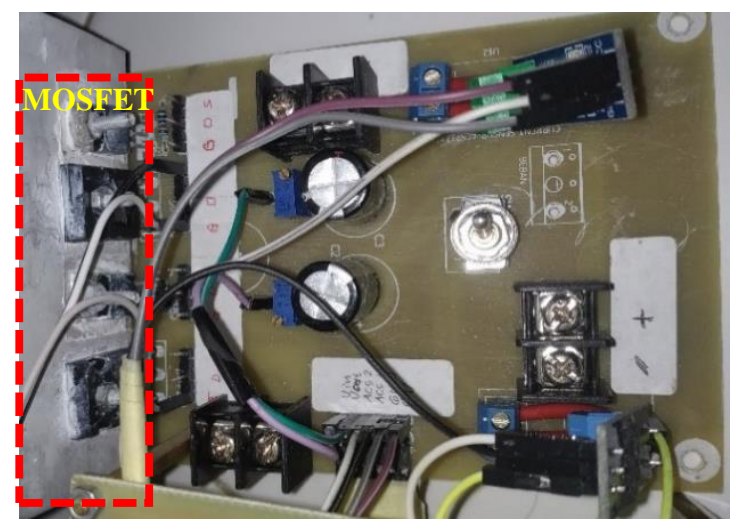

(b)

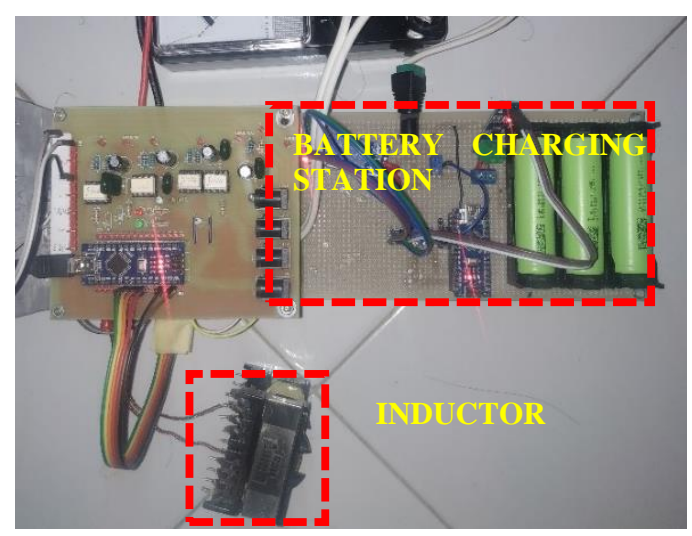

(c)

Fig. 12. Implementation of the converter (a) series MOSFET Driver (a) converter circuit (b) inductor and battery charging station

TABLE IV. USED COMPONENT FOR THE CONVERTER IMPLEMENTATION

\begin{tabular}{|l|l|}
\hline \multicolumn{1}{|c|}{ Component } & \multicolumn{1}{c|}{ Value } \\
\hline DC Supply & $10,8 \mathrm{~V}$ \\
\hline Microcontroller & Arduino NANO \\
\hline MOSFET N Channel & IRF 250 N \\
\hline MOSFET P Channel & IRFP 9540 \\
\hline Driver MOSFET & TLP 250 \\
\hline Power Supply for Driver Mosfet & $12 \mathrm{~V}$ \\
\hline Inductor & $440 \mu \mathrm{H}$ \\
\hline Inductor Core & ETD49 \\
\hline Input Capacitor & $1000 \mu \mathrm{F} 50 \mathrm{~V}$ \\
\hline Output Capacitor & $1000 \mu \mathrm{F} 50 \mathrm{~V}$ \\
\hline Resistor Load & $6,3 \Omega$ dan $2,7 \Omega$ \\
\hline Li-ion Battery & $2600 \mathrm{mAh}, 3$ cell \\
\hline Switching Frequency & $20 \mathrm{kHz}$ \\
\hline Output Voltage & 12,6 dan 5,4 V \\
\hline Voltage Sensor & Multiturn $100 \mathrm{k} \Omega$ \\
\hline Current Sensor & ACS 712 \\
\hline
\end{tabular}

After defining the parameters and components we are going to use, the next step is implementing or creating a set of converters using the components on the market. The parameter values of each component will be listed in the 
Table. 3 above. Next is the picture of the prototype that has been implemented. Figure 11 and 12 is an image of the whole prototype consisting of a series of drivers, converters, and a lithium-ion battery charging circuit. The driver is used to do the switching of the converter. Using a series of drivers, we can control the converter circuit without directly using the Arduino. Thus, improving its reliability.

\section{RESULTS AND DISCUSSION}

\section{A. Constant Current Test}

We carry out constant current testing on closed loop systems on the converter circuit. The converter will be done to test the load, the current in the converter can adjust so that the output current value of the converter is always the same. The test is conducted by using a modified resistive load change it every 30 seconds. This test is done 2 times with current value in forward power flow is $1.1 \mathrm{Amps}$ and in backward power flow is 1.6 Amps.



Time (Second)

Fig. 13. Forward power flow constant current test voltage (blue), current (orange)

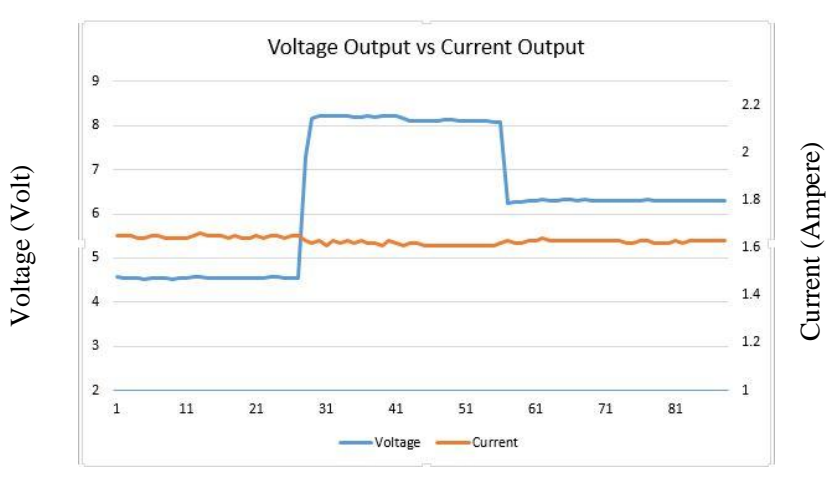

Time (Second)

Fig. 14. Backward power flow constant current test voltage (blue), current (orange)

The first step is to set the current set point of 1.1 Amps for the forward power flow and 1.65 Amps to backward power flow. To find out if the converter works according to the desired design, the converter is given a load that changes every 30 seconds to see if the resulting current remains the same. For part (a) on the forward mode in the current set of 1.1 Amps with a load of $12 \Omega, 8 \Omega$ and $10 \Omega$. It can be seen that the current value always remains 1.1 Amps and has a voltage value changed due to the changed load. When working in backward power flow, set the current at $1.65 \mathrm{Amps}$, then load will be changed every 30 seconds with a value of $3 \Omega, 5 \Omega$ and
$4 \Omega$. Then we can see the output current value is fixed but the output voltage in the converter changes according to the load.

\section{B. $\quad$ Charging Battery Test}

Battery charging tests are implemented with the aim of knowing the capabilities of the converters in real applications. The battery used is a three-cell lithium-ion battery with a maximum total voltage of 12.6 Volt with a capacity of 2600 mAh.

Testing is done on batteries with empty conditions with a nominal voltage of $3.7 \mathrm{~V}$. Then we charge the battery until it has reached its cut-off voltage suggested by the datasheet which is 12.6 Volt. Figure 15 below is the resulting graph of Li-ion battery charge. The battery charge process is carried out for approximately 87 minutes to achieve a 12.6 Volt value with a constant current of 1.1 Amps. When the battery reaches 12.6 volts, the battery is removed from the converter so that it does not experience overcharge. Then after the battery is removed, the voltage is dropped to 12.35 volt. This happened because the constant current method causes an over potential on the battery due to the interaction of the current with internal resistance to the battery.



Fig. 15. Battery charging results voltage (blue), current (orange)

\section{CONCLUSIONS}

Based on the calculation results, simulation and implementation of cascaded bidirectional buck-boost $\mathrm{dc}-\mathrm{dc}$ converter for the application of charging lithium-ion batteries we can draw conclusions that, implementation of the converter using closed loop feedback using a microcontroller can create a constant current value when programmed properly. At the time of implementation, the ripple current of the inductor has a value of $240 \mathrm{~mA}$ instead of $180 \mathrm{~mA}$. This is due to the impurity of the inductor component which results in a different ripple value from the simulation results. The implementation of bidirectional cascaded buck - boost converter has an average efficiency of $83 \%$ for buck mode and $81 \%$ for boost mode. Implementation of the converter used for charging Li-Ion battery with constant current method and current parameters 1.1 Amps and cut-off voltage 12.6 Volt work according to the design. After charging the battery for 93 minutes. Now the battery has a SOC value for about 90 $95 \%$ from the previous one which is only $40 \%$. This value is achieved by measuring the open circuit voltage. This is due to an overpotential that occurs in the charging process using a constant current method. 


\section{REFERENCES}

[1] A. Tomaszewska et. al., "Lithium-ion battery fast charging: A review," eTransportation, vol. 1, pp. 100011, Aug 2019.

[2] T. Horiba, "Lithium-Ion Battery Systems," Proc. IEEE, vol. 102, no. 6, pp. 939-950, Jun 2014.

[3] C. Patsios et al., "An integrated approach for the analysis and control of grid connected energy storage systems," Journal of Energy Storage, vol. 5, pp. 48-61, Feb 2016.

[4] M. A. Khan, A. Ahmed, I. Husain, Y. Sozer, and M. Badawy, "Performance Analysis of Bidirectional DC-DC Converters for Electric Vehicles," IEEE Trans. on Ind. Applicat., vol. 51, no. 4, pp. 3442-3452, Jul 2015.

[5] S. A. Gorji, A. Mostaan, H. Tran My, and M. Ektesabi, "Non-isolated buck-boost dc-dc converter with quadratic voltage gain ratio," IET Power Electronics, vol. 12, no. 6, pp. 1425-1433, Mei 2019.

[6] H. Fan, "Design tips for an efficient non-inverting buck-boost converter," pp. 8, 2014.

[7] S. A. Gorji, H. G. Sahebi, M. Ektesabi, and A. B. Rad, "Topologies and Control Schemes of Bidirectional DC-DC Power Converters: An Overview," IEEE Access, vol. 7, pp. 117997-118019, 2019.

[8] X. Chen, A. A. Pise, J. Elmes, and I. Batarseh, "Ultra-Highly Efficient Low-Power Bidirectional Cascaded Buck-Boost Converter for Portable PV-Battery-Devices Applications," IEEE Trans. on Ind. Applicat., vol. 55, no. 4, pp. 3989-4000, Jul 2019.

[9] Byungcho Choi, Wonseok Lim, Seungwon Choi, and Jian Sun, "Comparative Performance Evaluation of Current-Mode Control Schemes Adapted to Asymmetrically Driven Bridge-Type Pulsewidth Modulated DC-to-DC Converters," IEEE Trans. Ind. Electron., vol. 55, no. 5, pp. 2033-2042, Mei 2008.

[10] R. D. Pal and A. K. R. Paul, "Charge-discharge studies of lithium-ion batteries," pp. 5, 2015.

[11] I. U. Khalil, M. Ahsan, I. Ullah, A. Adnan, N. Khan, and S. Nawaz, "SOC prediction of Lithium-Ion Battery using Extended Kalman Filter," in 2018 International Symposium on Recent Advances in Electrical Engineering (RAEE), Islamabad, Pakistan, Okt 2018 